\title{
A New methodology of Nondestructive Testing for Quantitative Evaluation of Sigma Phase in Duplex Stainless Steels
}

\author{
Hudison Loch Haskel * ${ }^{*}$, Luciana Schmidlin Sanches ${ }^{b}$, Haroldo de Araujo Ponte $^{b}$ \\ aPrograma de Pós Graduação em Engenharia e Ciência dos Materiais, Universidade Federal do \\ Paraná, Curitiba, PR, Brasil \\ ${ }^{b}$ Engenharia Mecânica, Universidade Federal do Paraná, Curitiba, PR, Brasil
}

Received: October 19, 2018; Revised: February 11, 2019; Accepted: March 28, 2019

\begin{abstract}
Duplex Stainless Steels (DSSs) are widely used in the oil and gas industry. When the steel is subjected to a thermal gradient, as in welding may occur precipitation of intermetallic phases. Among these phases, there is the sigma phase, which even in small quantities reduces drastically the mechanical and corrosion resistance properties. According to some studies in the literature, the limit amount of sigma phase present in steel in welded joints must be in a maximum volume fraction of $2,5 \%$. In search to improve the detection sensitivity of the sigma phase, this paper presents results obtained by Linear Sweep Voltammetry (LSV) in Duplex Stainless Steel UNS S31803 as a Nondestructive Testing (NDT) model. The innovation in the application of this test is to use a microcell-based system that allows a reduced area of analysis obtaining density of currents in the order of microamperes and in the use of selective electrolytes to the elements of the oxides present in the intermetallic phases. With the use of these systems and through the optimization of control parameters it was possible to detect very low amounts of deleterious phases such as the sigma and chi phases.
\end{abstract}

Keywords: Deleterious Phases, Duplex Stainless Steel, Linear Sweep Voltammetry, microcell system.

\section{Introduction}

The effect of deleterious phases on the mechanical and corrosion properties on the Duplex Stainless Steels (DSSs) is well known and studied by many researchers. ${ }^{1-6}$ These phases may be formed during hot rolling process, components operation at certain temperatures and welding, which constitute a broad application of DSSs. ${ }^{7,8}$ Therefore, not only the knowledge of the effect of the intermetallic phases on the DSSs properties is necessary. It is also important to monitor these properties along the time.

The Double Loop Electrochemical Potentiokinetic Reactivation (DL-EPR) test is known to be able to detect the presence of microstructural changes due to precipitation of intermetallic phases and the chromium carbides precipitation in grain contours with focus on the Degree of Sensitization (DOS). ${ }^{9-12}$ This technique employs cyanide solutions and may present limitations due to sensitivity to the minimum content detectable of deleterious phases whose common consensus is defined as between 1 and $2 \%$ while the minimum value detected by a DL-EPR field probe is $8 \%$. ${ }^{13}$ Another important concern is the technique applicability in regions such as the Heat-Affected Zone (HAZ) in welding process, as the HAZ may presents small dimensions whereas the contact area commonly used in the DL-EPR technique is considerably larger, which could generate problems for applications of the technique to such approach.

*e-mail: hudisonhaskel@hotmail.com
Electrolytic etching based on hydroxides solutions are used for visual inspection mode and metallography analysis of intermetallic phases in the DSSs. This procedure presents, as main advantage, the possibility of a selective etching at different phases ${ }^{14,15}$ where applied anodic current acts as an oxidizing agent. As the film formed on the deleterious phases in DSSs is composed by oxides of its forming components (chromium and molybdenum), the application of anodic potential in hydroxide solution generates the selective dissolution of these oxides, thus ensuring the selectivity of the method. ${ }^{14,16}$ In a similar way, it is reported in the literature the use of microcells for the study of localized corrosion in metals and their alloys, the reduction of the area of analysis allows the comparison between microstructural characteristics and local electrochemical processes that could hardly be obtained in the study of global corrosion. ${ }^{17,18,19}$ In addition, there is a gain in the quality of the signal obtained from the possibility of high rates of mass transport from the working electrode, reduction of capacitive currents and reduction of Ôhmic drop ${ }^{20}$.

In this way, the present work innovates by consolidating the use of microcells and selective electrolytes for the development of a high sensitivity test methodology for detecting small amounts of deleterious phases (sigma and chi phases) presented in DSS UNS S31803 structure. This methodology is based on a known electrochemical technique consolidated in the literature (Linear Sweep Voltammetry, LSV). The use of the microcell allows the analysis of a local micrometric 
area providing the high sensitivity of the technique, which is translated by the low currents obtained. Through the use of selective electrolytes to the elements present in the deleterious phases it is guaranteed that this current comes from the dissolution of the oxides of these elements.

\section{Materials and Methods}

The tested material was a duplex stainless steel UNS S31803, which chemical composition was obtained by quantitative chemical analysis using different standard methods. This DSS was supplied in bar-shaped size of $27.5 \mathrm{~cm}$ x $10 \mathrm{~cm} \times 0.5 \mathrm{~cm}$ and subjected to aging heat treatment at heating conditions shown in Table 1 . The selected temperature corresponds to that for the highest kinetics reactions for sigma phase precipitation.

The linear voltammetry test was performed in a cell of three electrodes with $10 \mathrm{~mL}$ electrolyte capacity. The working electrode were the UNS S3180, a Calomel

Table 1. Conditions of heat treatments

\begin{tabular}{lc}
\hline Samples & Aging time \\
\hline 1 & Solubilization at $1050{ }^{\circ} \mathrm{C}$ \\
2 & $870^{\circ} \mathrm{C}-5$ minutes \\
3 & $870^{\circ} \mathrm{C}-10$ minutes \\
4 & $870{ }^{\circ} \mathrm{C}-15$ minutes \\
5 & $870{ }^{\circ} \mathrm{C}-20$ minutes \\
6 & $870^{\circ} \mathrm{C}-25$ minutes \\
7 & $870^{\circ} \mathrm{C}-30$ minutes \\
8 & $870{ }^{\circ} \mathrm{C}-60$ minutes \\
\hline
\end{tabular}

Saturated Electrode (CSE) was used as reference electrode and a platinum wire as auxiliary. The test was performed at different dots samples with contact area of $0.0054 \mathrm{~cm}^{2}$. The attack that occurs on the mentioned area does not modify the structure of the material tested therefore been considered as a Nondestructive Testing (NDT).

Electrolytic solutions of $\mathrm{KOH}$ were used in different concentrations $(0.3,0.5,1,2$ and $3 \mathrm{~mol} / \mathrm{L})$. Different scan rates were also employed being performed from $-0.7 \mathrm{~V}$ to $+0.7 \mathrm{~V}$. The temperature was maintained at $25^{\circ} \mathrm{C}$. To avoid the displacement of currents in the initial stage of the experiment, before each measurement of voltammetry, the samples were subjected to a conditioning time of 8 seconds at the potential of $-0.7 \mathrm{~V}$. After each measurement the electrolyte and the electrode position was changed, allowing measurements in different sample locals. In each sample the measurements were performed in triplicates. The used experimental apparatus concept is shown in Figure 1. The equipment used to perform linear voltammetry in this work was a Gamry potentiostat model Reference 600 .

After the heat treatment, samples were taken to perform metallographic analysis. These samples were embedded in hot curing resin, sanded up to 1200 mesh and polished with alumina solution up to 0.25 micra. For the observation of the microstructure an electrolytic etching with a $10 \% \mathrm{KOH}$ solution was carried out, subject to a voltage of $2 \mathrm{~V}$ in direct current for 60 seconds. The observation of the images was performed in an OLYMPUS optical microscope, MODEL BX-51M, and the treatment of these images was done by analySIS 5.0 software.

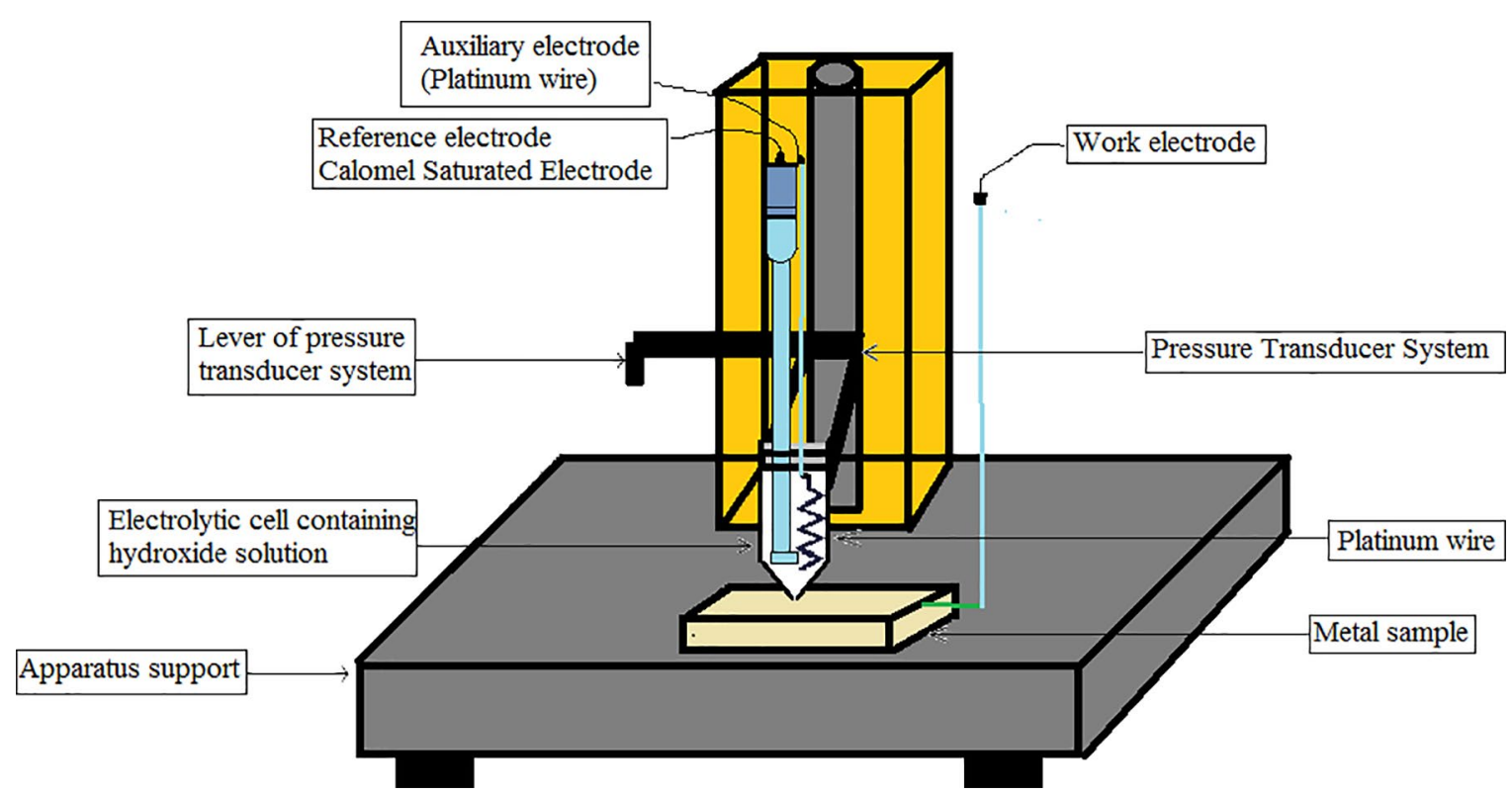

Figure 1. Schematic representation of the experimental apparatus used to perform Linear Sweep Voltammetry. 


\section{Results and Discussion}

\subsection{Microstructural Analysis}

Many electrolytic etchings are found in the literature to selectively reveal the presence of deleterious phases in the structure of stainless steels. Among these, etchings alkaline solutions have the most prominence with reactive $\mathrm{KOH}$ being the most used and known to selectively reveal the sigma phase. ${ }^{21} \mathrm{NaOH}$ solutions have been considered by possibility of revealing the contour between the austenitic and ferritic phases (with a slight etching on the ferrite) as well as the possibility of distinguishing between sigma and chi phases using the correct choice of attack parameters. ${ }^{22}$ Figure 2 shows the microstructures of UNS S31803 steel etching in $\mathrm{KOH}$ solution. The images were submitted to quantitative analysis following the recommendations of ASTM E1245-03, standard ${ }^{23}$. The results found are contained in Table 2.

The UNS S31803 steel microstructure for different heat treatment times were obtained by Scanning Electron Microscopy (SEM), in backscattered electron mode without etching and is shown in Figure 3. From the sample 3 it is possible to observe the presence of precipitation of sigma
Table 2. Percentage of intermetallic phases precipitated in area

\begin{tabular}{ccc}
\hline Samples & Heat Treatment time & $\begin{array}{c}\text { \% Content } \\
\text { precipitated in area }\end{array}$ \\
\hline 01 & Solubilization a $1050^{\circ} \mathrm{C}$ & 0.00 \\
02 & 5 minutes & 0.00 \\
03 & 10 minutes & $0,2 \pm 0,0$ \\
04 & 15 minutes & $0,9 \pm 0,1$ \\
05 & 20 minutes & $4,1 \pm 0,2$ \\
06 & 25 minutes & $4,9 \pm 0,2$ \\
07 & 30 minutes & $6,3 \pm 0,9$ \\
08 & 60 minutes & $14,2 \pm 1,0$ \\
\hline
\end{tabular}

and chi phases, the lighter phases being rich in elements of greater atomic number such as molybdenum. The chi phase is indicated by red arrows, while the sigma phase is indicated by white arrows. The chi phase precipitation precedes the sigma phase precipitation and subsequently the transformation of chi into sigma is reported and is therefore a metastable phase in DSSs. The incipient chi phase precipitation to the sigma phase is explained by the coherent interface between the chi phase (Body Centered Cubic) and the ferritic phase (also Body Centered Cubic) which present a low energy,
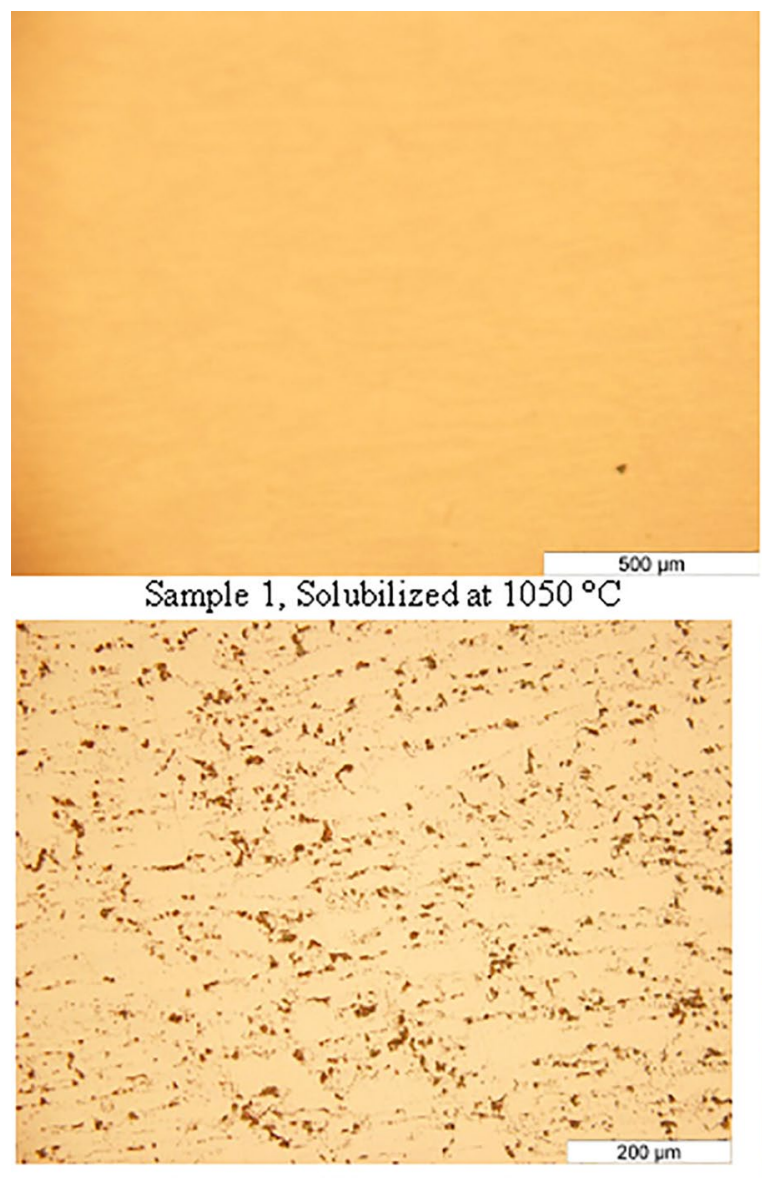

Sample 5, 20 minutes of aging

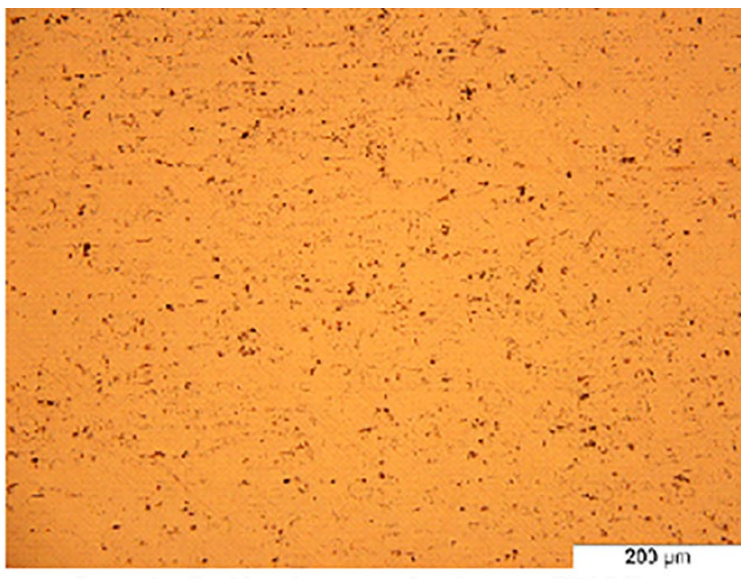

Sample 3,10 minutes of aging at $870^{\circ} \mathrm{C}$

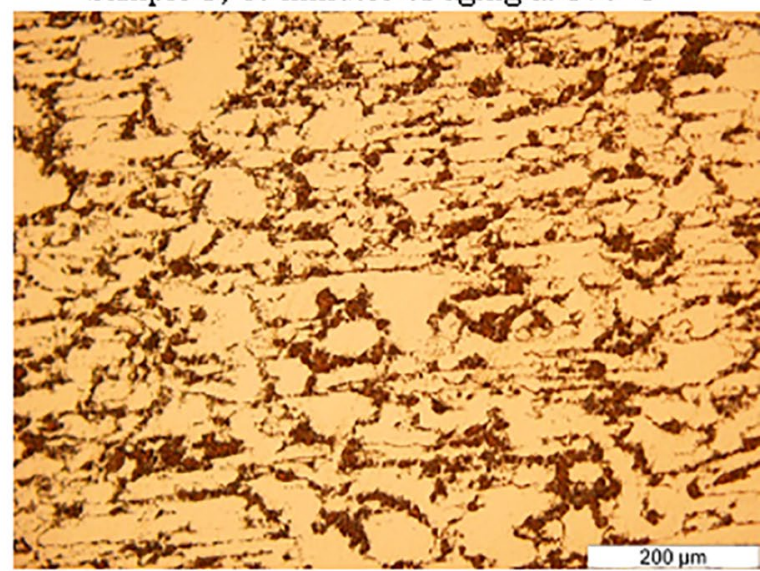

Sample 8,60 minutes of aging at $870^{\circ} \mathrm{C}$

Figure 2. Duplex Stainless Steel microstructure subjected to different heat treatment times. Electrolytic etching with $\mathrm{KOH} 10 \%$ at $60 \mathrm{~s}$. 
favoring precipitation of chi before sigma whose structure is Tetragonal Body Centered.

In addition to the intermetallic phases, the presence of secondary austenite $\left(\gamma_{2}\right)$ was also observed in Figure 3. This phase is indicated by blue arrows and is derived from the eutectotide reaction: ferrite $\rightarrow$ sigma + secondary austenite $\left(\alpha \rightarrow \sigma+\gamma_{2}\right)$.

Electrolytic etching employing hydroxide solution are known and used to reveal selectively the sigma phase as was done here. However, there is still doubt that only the

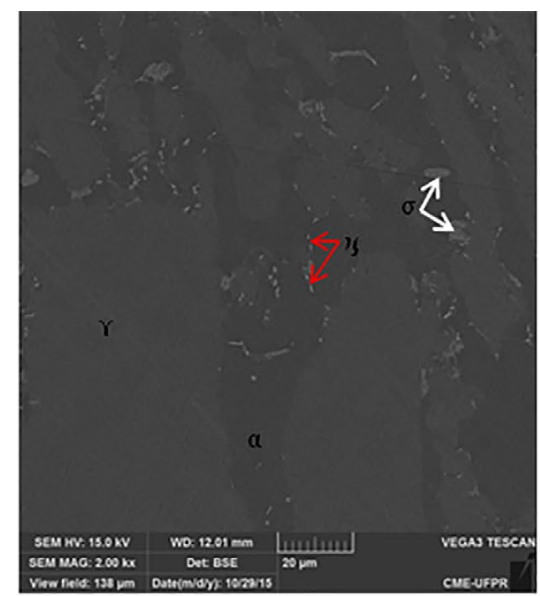

Sample 3,10 minutes of aging at $870^{\circ} \mathrm{C}$

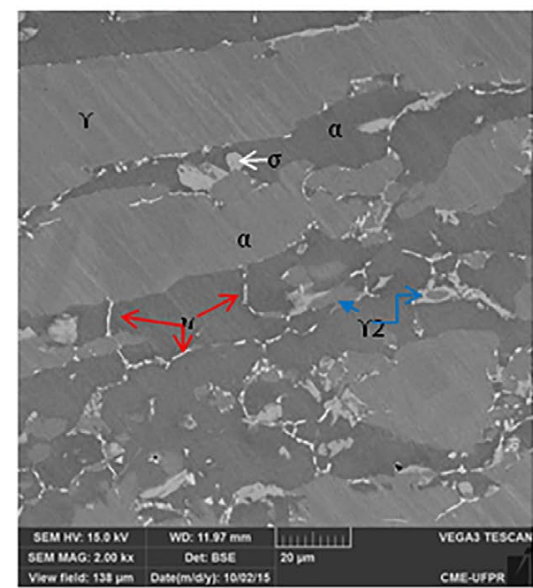

Sample 5, 20 minutes of aging at $870^{\circ} \mathrm{C}$

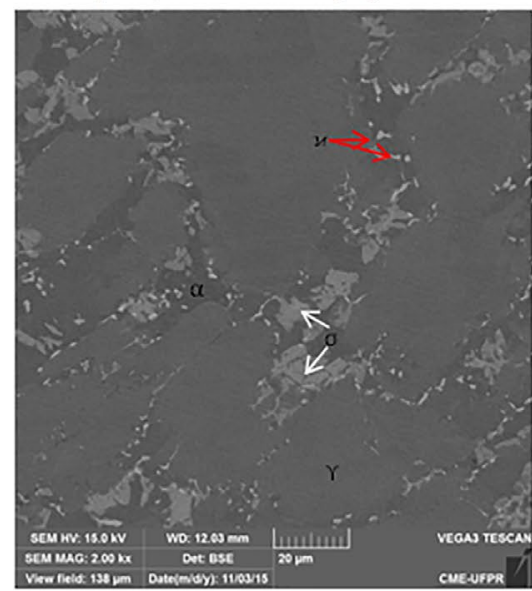

Sample 7, 30 minutes of aging at $870^{\circ} \mathrm{C}$

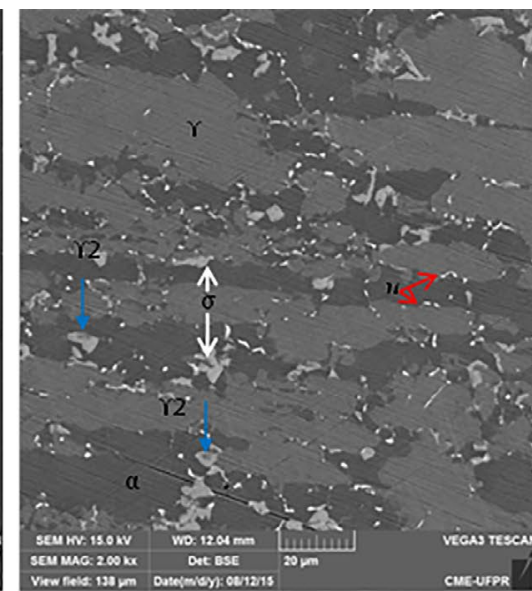

Sample 4,15 minutes of aging at $870^{\circ} \mathrm{C}$

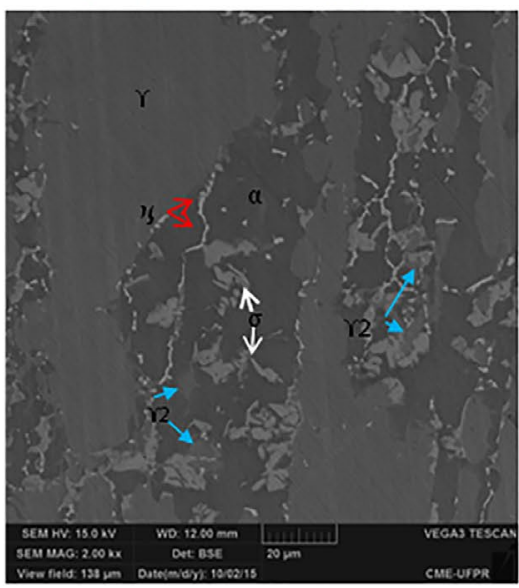

Sample 6,25 minutes of aging at $870^{\circ} \mathrm{C}$

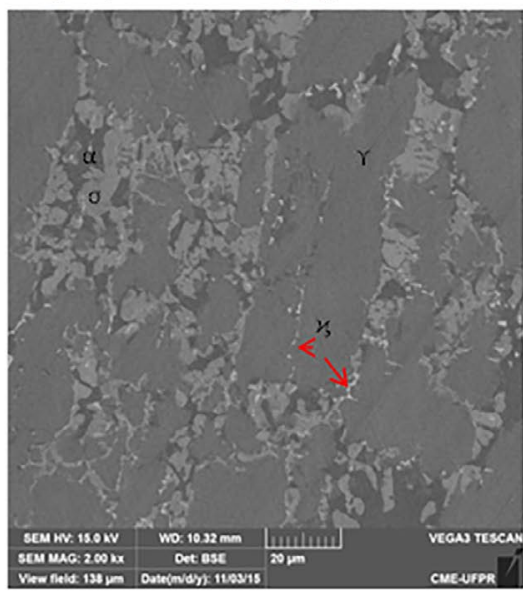

Sample 8,60 minutes of aging at $870^{\circ} \mathrm{C}$

Figure 3. Microstructures of UNS S31803 steel aged isothermally at 870 in different times (Images by SEM). 
sigma phase is revealed during this type of etching, since it is based in selective oxidation of alloy elements chromium and molybdenum, elements also present in other phases of DSSs.

Studies in the literature that take into account the comparison of the sigma phase fraction obtained by quantitative metallography and simulations via thermocalc and dictra sotwares lead to the conclusion that it may occur the overestimation of the fractions values obtained by metallography ${ }^{24}$. The microstructures obtained by SEM of samples 5 and 8 , after electrolytic attack with $10 \% \mathrm{KOH}$, $2 \mathrm{~V}$ for $60 \mathrm{~s}$, are shown in Figure 4 where in comparison with the images of Figure 3 it is possible to notice that the attack occurs severely both phases: sigma phase and the most refined structure, chi phase. Therefore, not only the sigma phase is being attacked, but also the chi and other intermetallic phases that are present, so that the percentage calculated by means of optical analysis, refers not only to sigma but to sigma + chi.

\subsection{Linear Sweep Voltammetry in Potassium Hydroxide solution}

The potential of the linear voltammetry technique for the detection of intermetallic phases in DSS UNS S31803 has already been analyzed in a previous work ${ }^{25}$ and the best parameters of analysis were the peak current density and its corresponding charge density, the latter being possible to correlate directly with the mechanical properties.

In order to find the optimized conditions for the control parameters, LSV technique was performed at different

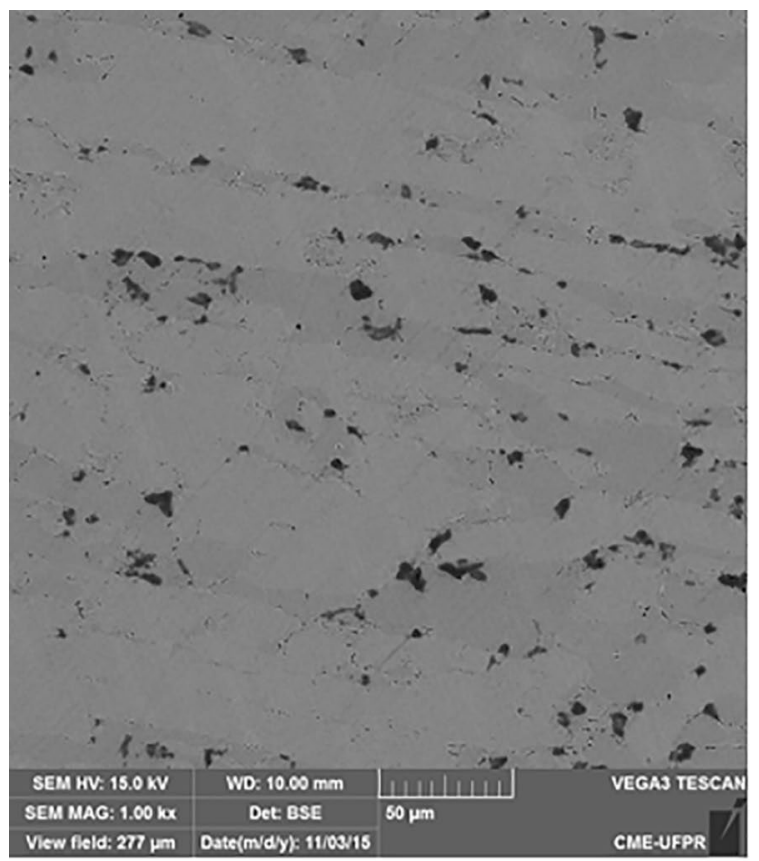

Sample 5 concentrations of $\mathrm{KOH}$ electrolyte. Some voltamograms for UNS S31803 steel in different heat treatment conditions in $0.3 \mathrm{~mol} / \mathrm{L} \mathrm{KOH}$ solution can be visualized in Figure 5.

In these voltammetry it was possible to note the presence of a peak, at approximately $0.2 \mathrm{~V}$. However there is no way to assert with confidence about the phases that are providing the current density obtained in the voltammetry test, since the voltammetric profile obtained was the same for all conditions of heat treatment.

For the electrolyte concentration of $3 \mathrm{~mol} / \mathrm{L}$, as shown in Figure 6, the voltammetric profile of samples 1 and 2 was the same as for lower concentrations such as $0.3 \mathrm{~mol} / \mathrm{L}$, with peak current density one order of magnitude higher in $0.07 \mathrm{~V}$.

From sample 3 (10 minutes of heat treatment) where the precipitation of intermetallic phases begins, it is observed the modification in the voltammetric profile with the formation of three peaks, been the first in $0.045 \mathrm{~V}$ (10 min. of heat treatment), where the precipitation of intermetallic phases begins, the second at 0.075 and the third one at $0.15 \mathrm{~V}$, as shown in Figure 7.

Sample 4 also presents 3 peaks, at the same potential range $(0.045,0.07$ and $0.15 \mathrm{~V}$, respectively), being the first peak (in $0.045 \mathrm{~V}$ ) which presented higher current density. Similar behavior was observed for sample 6 , however with the peak at $0.07 \mathrm{~V}$ with higher current density.

The voltammograms obtained for samples 7 and 8 (30 and $60 \mathrm{~min}$ of heat treatment) are shown in Figure 8. These voltammograms presented peaks at approximately 0.07 and $0.15 \mathrm{~V}$, wherein the peak at 0.07 presented higher current

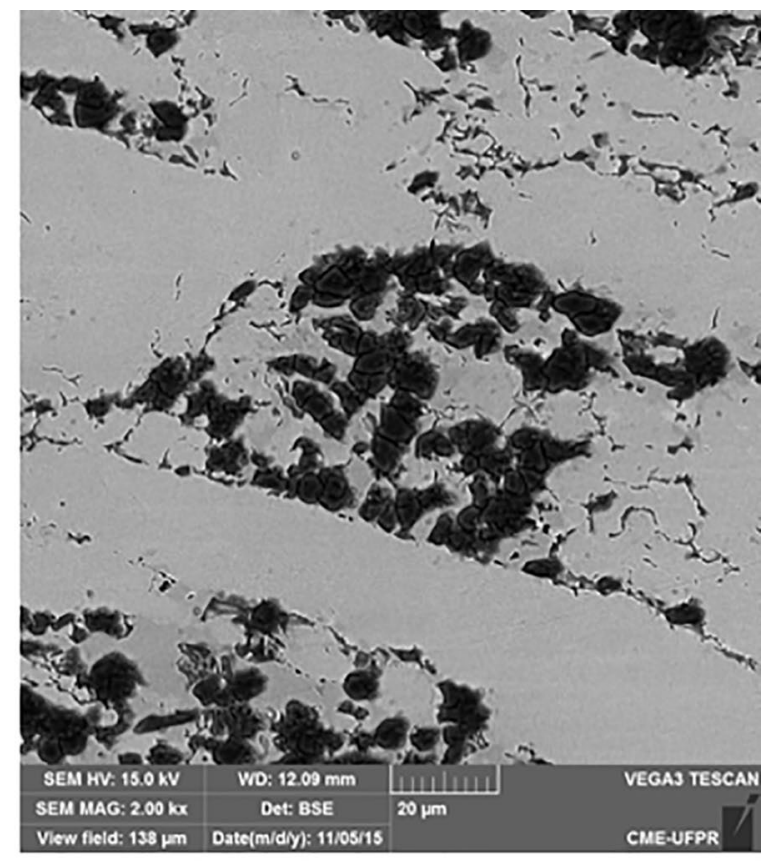

\section{Sample 8}

Figure 4. Microstructure of UNS S 31803 steel and different conditions of thermal treatment by SEM. Etching with $10 \% \mathrm{KOH}, 2 \mathrm{~V}$ and 60 seconds. 

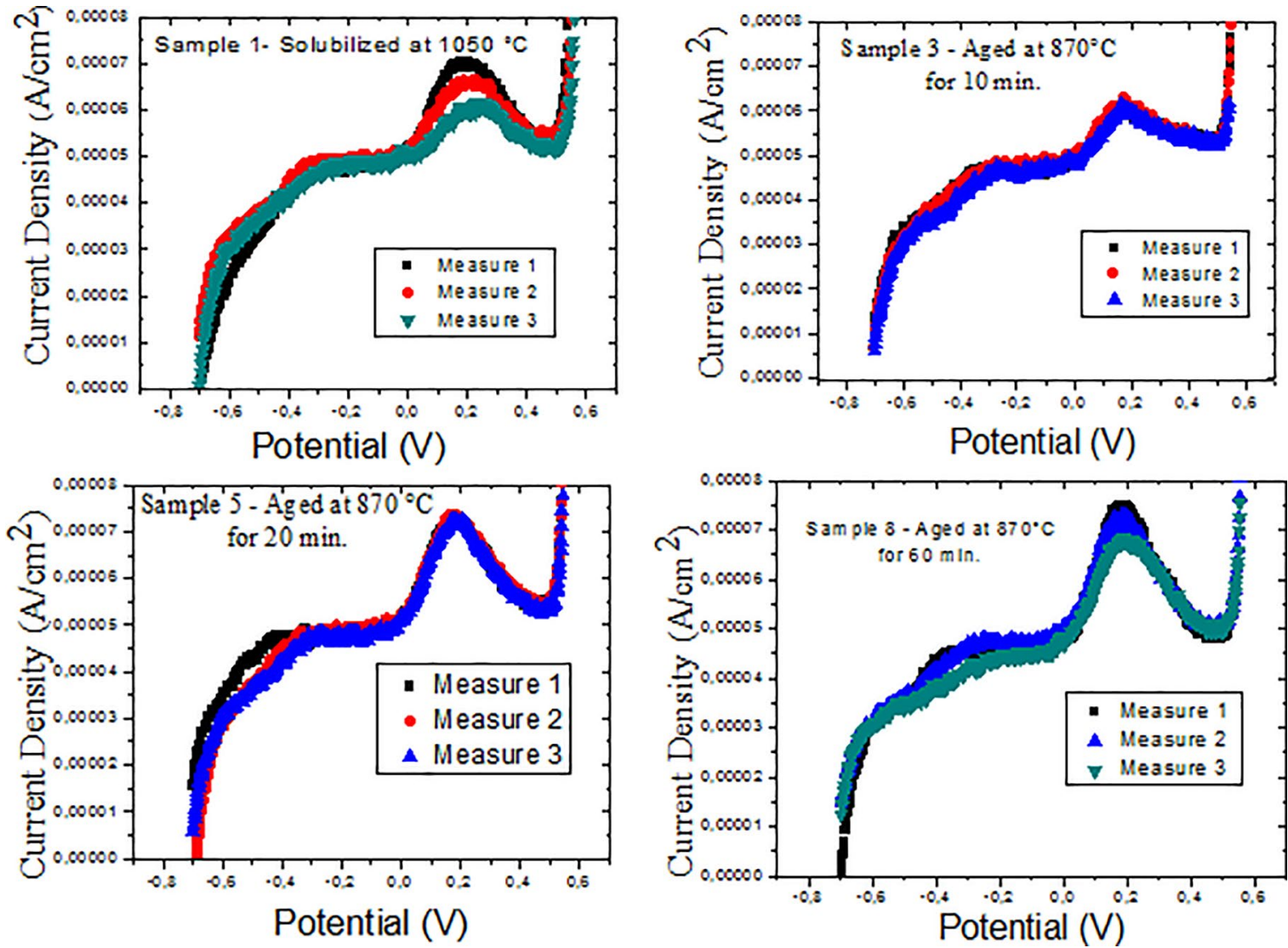

Figure 5. Linear Sweep Voltammetry of steel UNS S 31803 for different heat treatment conditions in $0.3 \mathrm{~mol} / \mathrm{L} \mathrm{KOH}$ solution and 2 $\mathrm{mV} / \mathrm{s}$ of scan rate.
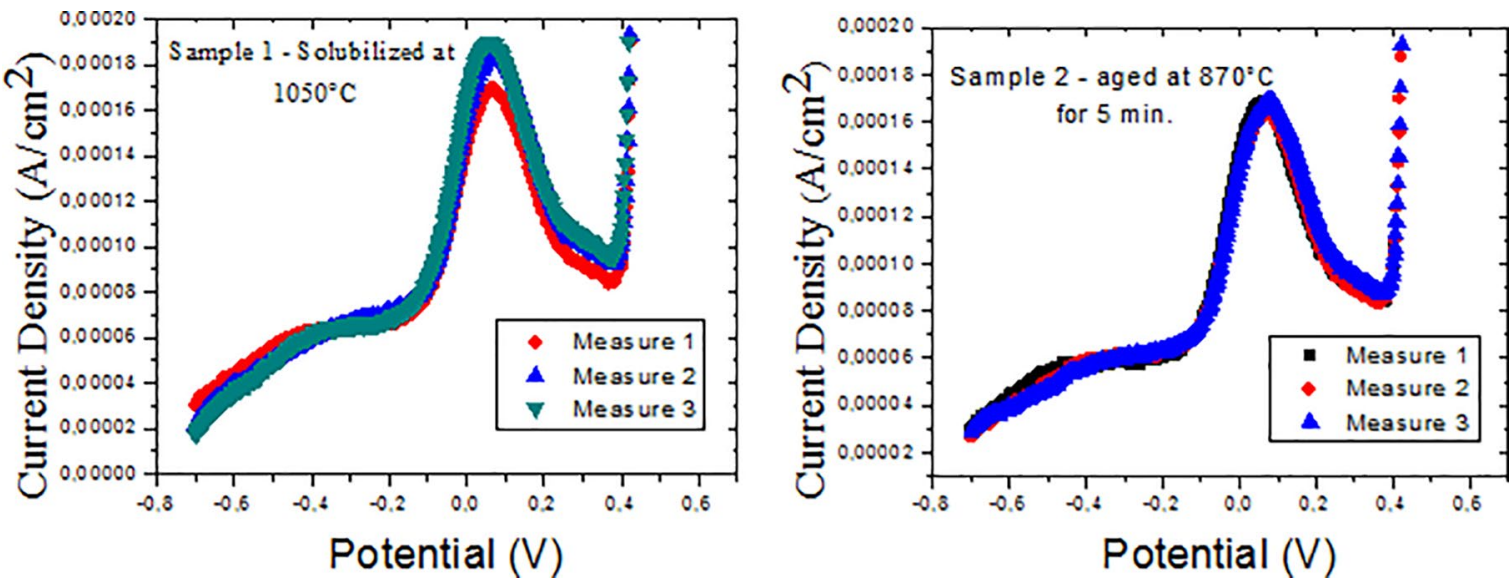

Figure 6. Linear Sweep Voltammetry of steel UNS S31803 in different heat treatment conditions in $3 \mathrm{~mol} / \mathrm{L} \mathrm{KOH}$ solution and $2 \mathrm{mV} / \mathrm{s}$ scan rate.

density. However, the current peak at 0.045 was not observed, a temporary phenomenon indicating its relation with some metastable phase such as the chi phase, which is a metastable phase of DSSs ${ }^{16}$ as well as the appearance of the third peak at $0.15 \mathrm{~V}$ should be related to sigma phase precipitation.

\subsection{Effect of the electrolyte concentration on the charge density profile}

A change was observed in the voltammetric profile obtained for the UNS S31803 steel occurred for the different concentrations of the reagent used, so this modification 

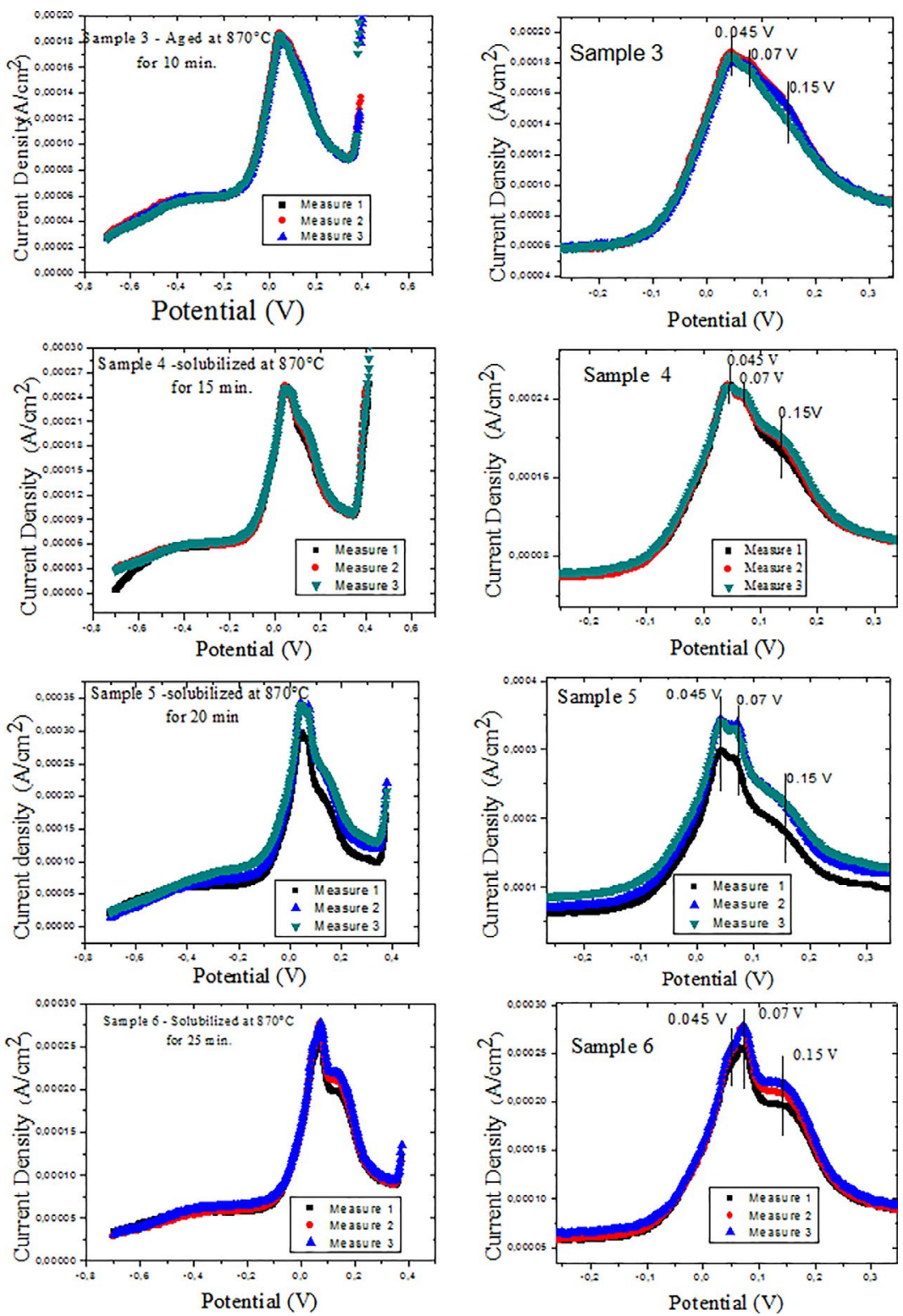

Figure 7. Linear Sweep Voltammetry of steel UNS S31803 for different heat treatment conditions in $3 \mathrm{~mol} / \mathrm{L} \mathrm{KOH}$ solution and $2 \mathrm{mV} / \mathrm{s}$ of scan rate. On the right is the zoom of the region where the current peaks occurred at $0.045,0.07$ and $0.15 \mathrm{~V}$.

should be reflected in the charge density analysis parameter. Figure 9 shows the charge density profile obtained for different concentrations of $\mathrm{KOH}$ in order to detect possible modifications in this profile with increasing electrolyte concentration. It should be noted that at concentrations where only one peak was obtained, the charge density was calculated by half peak integral to ensure that only the charge of nucleation, coalescence and film growth was being calculated. For electrolyte concentrations where three peaks were obtained the charge density was calculated using the corresponding area up to the second current density peak.

Based on these results it was possible to note that the charge density increases to higher electrolyte concentrations for all samples. However, it was noted decrease in charge density for samples 1,2 and 3. And for lower electrolyte concentrations, such as 0.3 and $0.5 \mathrm{~mol} / \mathrm{L}$, the charge density decrease for samples 7 and 8 ( 30 and $60 \mathrm{~min}$ ). This behavior was not observed at higher electrolyte concentrations, where the increase in charge density occurs for these samples.

The decrease in charge density for samples 1 and 2 has already been discussed previously and refers to the rebalancing between the ferrite and austenite fractions in DSSs structure. ${ }^{25}$

This behavior difference can be observed by the charge density profiles for the concentration of 0.3 and $2 \mathrm{~mol} / \mathrm{L}$ alone as shown in Figure 9 b) and c). 

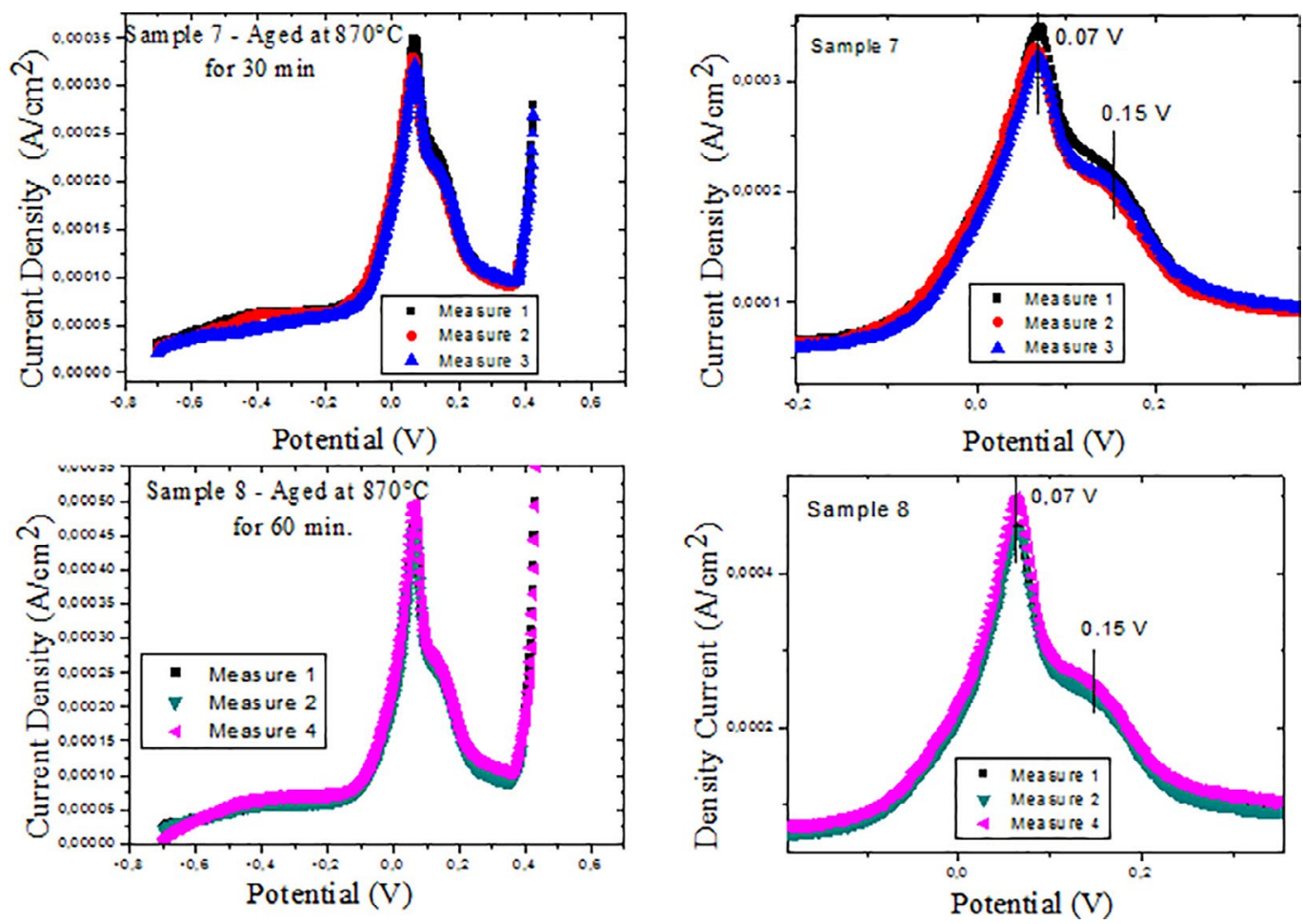

Figure 8. Linear Sweep Voltammetry of steel UNS S31803 for different heat treatment conditions in $3 \mathrm{~mol} / \mathrm{L} \mathrm{KOH}$ solution and $2 \mathrm{mV} / \mathrm{s}$ scan rate.
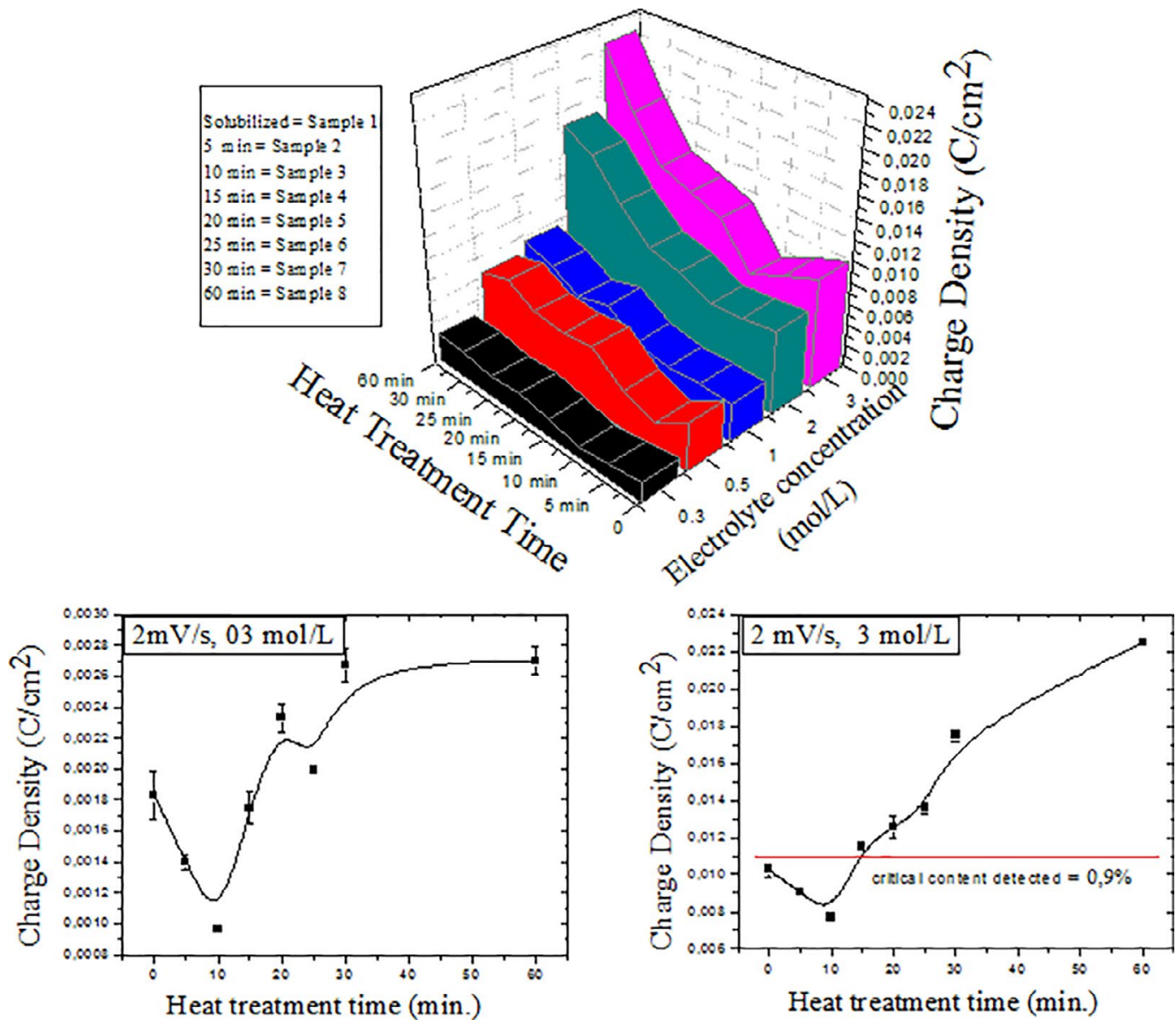

Figure 9. Effect of Concentration Electrolyte $(\mathrm{KOH})$ on the charge density profile of the analyzed samples. a) Effect on the charge density profile for various concentrations of the electrolyte, b) and c) effect for two concentrations isolated 0.3 and $3 \mathrm{~mol} / \mathrm{L}$, respectively. Scan rate employed $2 \mathrm{mV} / \mathrm{s}$. 
In this way, it was possible to consider that by employing higher concentrations such as $3 \mathrm{~mol} / \mathrm{L}$ it could be detected very low deleterious phase contents (less than $1 \%$ ) by means of charge density parameter, as is the case of sample $4(0.9 \%$ of sigma phase).

\subsection{Scan rate effect on the charge density profile}

Scan rate effect on the charge density profile is shown in Figure 10 where the charge density values tend to increase with decreasing in scan rate and the decrease in charge density for samples 1, 2 is noted. However, for some conditions, the increase in charge density for sample 3 occurred. The behavior difference for the charge density profile between the scan rate range analyzed, $10 \mathrm{mV} / \mathrm{s}$ to $1 \mathrm{mV} / \mathrm{s}$ is shown in Figure 10b) and c).

As shown the Figures $10 \mathrm{~b}$ ) and c) it is possible to note that slower scan rates provide a better distinction between samples with lower intermetallic phase contents and it is evident that with the scanning speed of $1 \mathrm{mV} / \mathrm{s}$ it is possible to differentiate samples with phase sigma from $0.2 \%$ (sample 3, $10 \mathrm{~min}$. of heat treatment).

The Figure 11 a) shows a limiting condition that was obtained for the concentration of $3 \mathrm{~mol} / \mathrm{L}$ and $1 \mathrm{mV} / \mathrm{s}$, in which it is possible to notice that there is an expressive increase in charge density of sample 2 for sample 3 ( 0 to $0,2 \%$ of intermetallic phases $\sigma$ and $x$ ). However, from this sample occurs the formation of a plateau where the charge density remains constant. Figure $11 \mathrm{~b}$ ) shows that the charge density does not follow the increase in peak current density.

The charge density as a function of the deleterious phase content obtained by quantitative metallography is shown in Figure 12, where it is possible to observe an increase with the increase of the deleterious phase content in Figure 12 a) and the distinction between samples with contents lower
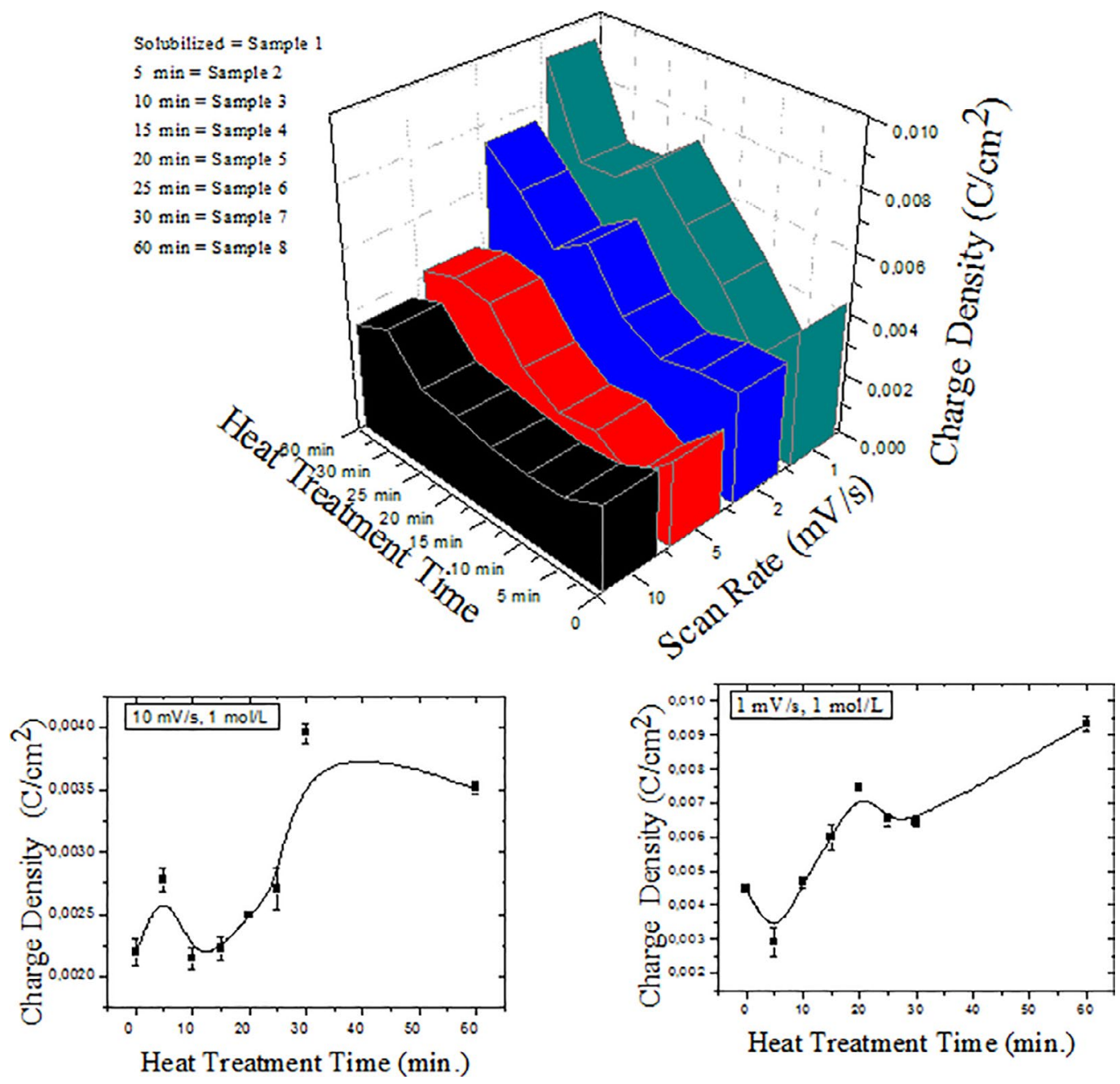

Figure 10. Scan rate effect on the charge density profile of the samples analyzed. a) Effect on the charge density profile for various scan rate. b) and c) For two scan rates b) $10 \mathrm{mV} / \mathrm{s}$ and c) $1 \mathrm{mV} / \mathrm{s}$. 

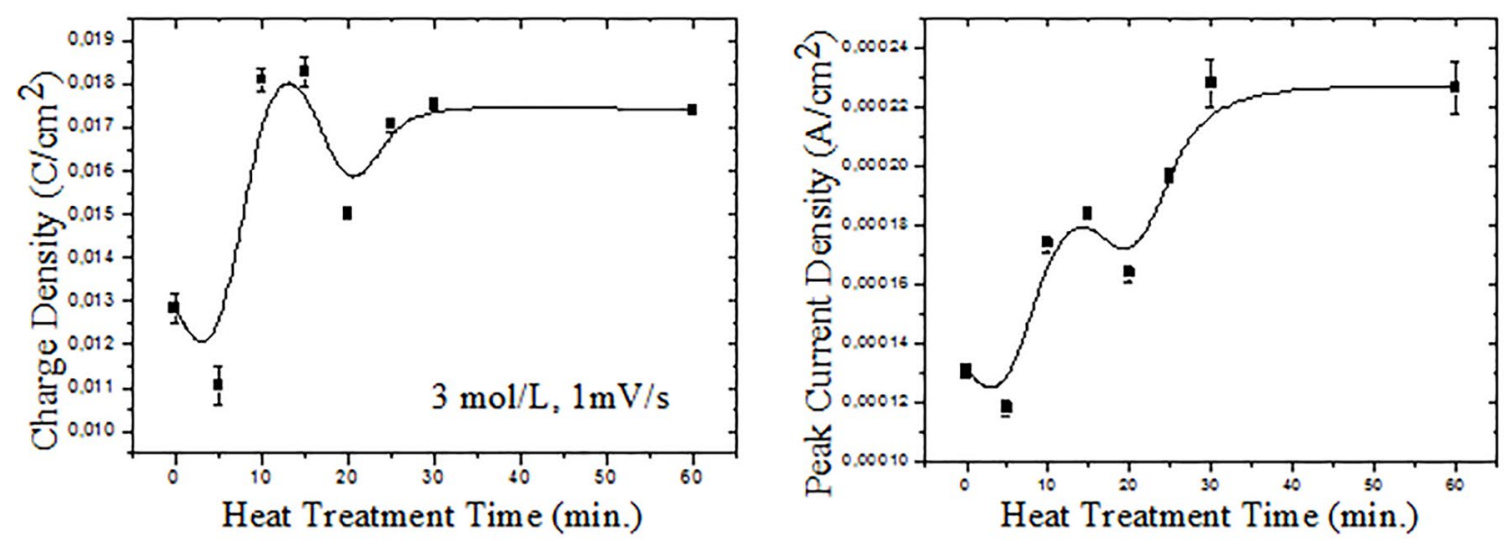

Figure 11. a) Charge density profile for the condition of $3 \mathrm{~mol} / \mathrm{L}$ and $1 \mathrm{mV} / \mathrm{s}$ b) peak current density for the measurements obtained in a).
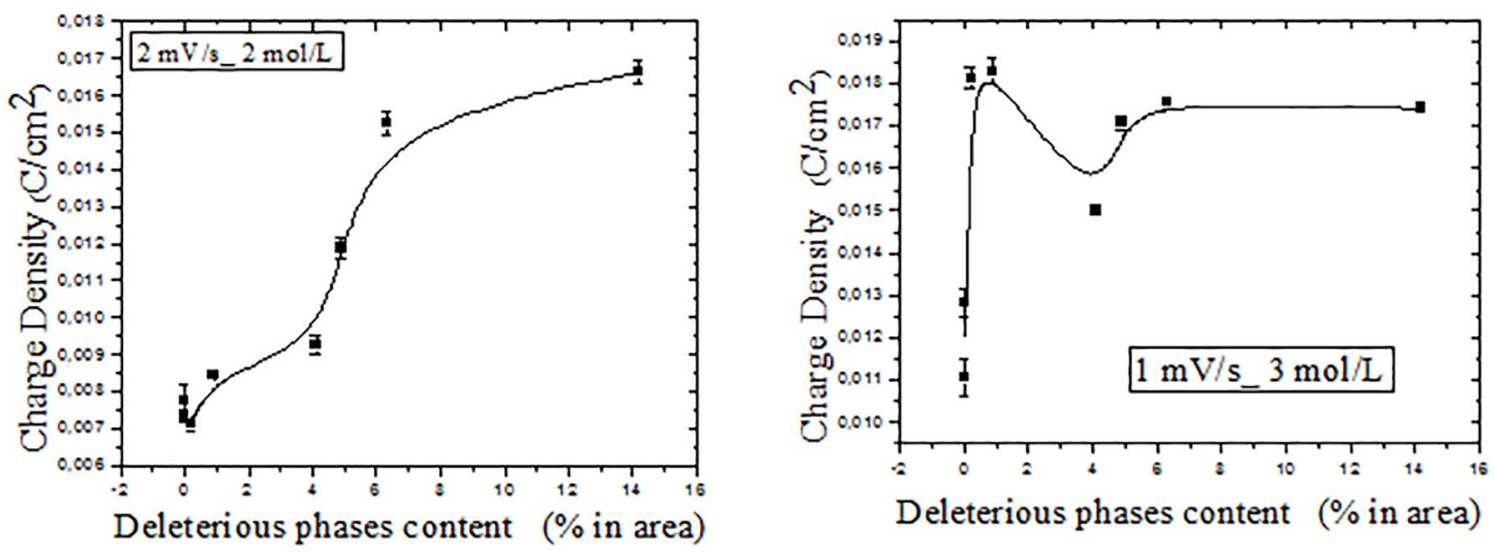

Figure 12. Density of charge in relation to the deleterious phase content of the samples obtained for conditions a) of $2 \mathrm{molar}$ and $2 \mathrm{mV} / \mathrm{s}$ b) 3 molar and $1 \mathrm{mV} / \mathrm{s}$.

than $0,9 \%$ and in Figure $12 \mathrm{~b}$ ) the distinction between samples with $0.2 \%$ of deleterious phases and the formation of a plateau with the increase of the content of deleterious phases, showing that optimal conditions can be obtained by control of scan rate and electrolyte concentration.

\section{Conclusions}

The LSV technique, applied with appropriated selective electrolytes and conditions (scan rate and electrolyte concentration), presents high sensitivity to the presence of intermetallic phases in DSSs structure and could be considered for NDT.

The sensitivity of the technique is mainly due to the choice of the electrolyte selectivity and the use of the reduced electrode area (microcell-based system).

The choice of higher concentrations and lower scan rates allowed the detection of intermetallic phase contents lower than $0.9 \%$ and in some cases $0.2 \%$.

This new testing methodology can be reproduced to other experimental systems in which the reagent employed exhibits selectivity to the deleterious phases or constituents.

\section{References}

1. Lopez N, Cid M, Puiggali M. Influence of s-phase on mechanical properties and corrosion resistance of duplex stainless. Corrosion Science. 1999;41(8):504-520.

2. Moura VS, Lima LD, Pardal JM, Kina AY, Corte RRA, Tavares SSM. Influence of microstructure on the corrosion resistance of the duplex stainless steel UNS S31803. Materials Characterization. 2008;59(8):1127-1132.

3. Chandra K, Singhal R, Kain V, Raja VS. Low temperature embrittlement of duplex stainless steel: Correlation between mechanical and electrochemical behavior. Materials Science and Engineering: A. 2010;527(16-17):3904-3912.

4. Chen TH, Weng KL, Yang JR. The effect of high-temperature exposure on the microstructural stability and toughness property in a 2205 duplex stainless steel. Materials Science and Engineering: A. 2002;338(1-2):259-270.

5. Marques IJ, Vicente AA, Tenório JAS, Santos TFA. Double Kinetics of Intermetallic Phase Precipitation in UNS S32205 Duplex Stainless Steels Submitted to Isothermal Heat Treatment. Materials Research. 2017;20(Suppl 2):152-158. 
6. Huallpa EA, de Monlevade EF, Sánchez JC, Campos MA, Padovese L, Goldenstein H. Use of Magnetic Barkhausen Noise (MBN) to Follow Up the Formation of Sigma Phase in Saf2205 (UNS S31803) Duplex Stainless Steel. Materials Research. 2016;19(5):1008-1016.

7. Badji R, Bouabdallah M, Bacroix B, Kahloun, Belkessa B, Maza $\mathrm{H}$. Phase transformation and mechanical behavior in annealed 2205 duplex stainless steel welds. Materials Characterization. 2008;59(4):447-453.

8. Sieurin H, Sandström R. Sigma phase precipitation in duplex stainless steel 2205. Materials Science and Engineering: A. 2007;444(1-2):271-276.

9. Amadou T, Sidhom H, Braham C. Double loop electrochemical potentiokinetic reactivation test optimization in checking of duplex stainless steel intergranular corrosion susceptibility. Metallurgical and Materials Transactions A. 2004;35(11):34993513.

10. Gao J, Jiang Y, Deng B, Zhang W, Zhong C, Li J. Investigation of selective corrosion resistance of aged lean duplex stainless steel 2101 by non-destructive electrochemical techniques. Electrochimica Acta. 2009;54(24):5830-5835.

11. Lo KH, Kwok CT, Chan WK. Characterisation of duplex stainless steel subjected to long-term annealing in the sigma phase formation temperature range by the DLEPR test. Corrosion Science. 2011;53(11):3697-3703.

12. Č́ihal V, Štefec R. On the development of electrochemical potentiokinetic method. Electrochimica Acta. 2001;46(2425):3867-3877.

13. Barreto ADG, Andrade TC, Silva CC, Miranda HC. Utilização do equipamento de ensaio EPR-DL de campo na deteç̧ão de fase sigma. Tecnologia em Metalurgia, Materiais e Mineração. 2014;11(2):146-154.

14. Gilman BJJ. Electrolytic etching - the sigma phase steels. Transactions of the A.S.M. 1951;44:566-600.
15. Potgieter JH, de Visser P. Potentiostatic etching of duplex stainless steels and high chromium white cast irons. Materials Science and Technology. 1993;9(4):336-342.

16. Grosebeck EC. Metallographic Etching Reagents. III: For Alloy Steels. Washington: Bureau of Standards; 1925.

17. Lohrengel MM, Moehring A, Pilaski M. Electrochemical surface analysis with the scanning droplet cell. Fresenius Journal of Analytical Chemistry. 2000;367(4):334-339.

18. Lister TE, Pinhero PJ. Microelectrode Array Microscopy: Investigation of Dynamic Behavior of Localized Corrosion at Type 304 Stainless Steel Surfaces. Analytical Chemistry. 2005;77(8):2601-2607.

19. Mennucci MM, Sanchez-Moreno M, Aoki IV, Bernard MC, de Melo HG, Joiret S, et al. Local electrochemical investigation of copper patina. Journal of Solid State Electrochemistry. 2012;16(1):109116.

20. Marcus P, Mansfeld F, eds. Analytical Methods in Corrosion Science and Engineering. Boca Raton: CRC Press; 2006.

21. Chan KW, Tjong SC. Effect of Secondary Phase Precipitation on the Corrosion Behavior of Duplex Stainless Steels. Materials (Basel). 2014;7(7):5268-5304.

22. Jackson EMLEM, de Visser PE, Cornish LA. Distinguishing between Chi and Sigma phases in duplex stainless steels using potentiostatic etching. Materials Characterization. 1993;31(4):185190.

23. ASTM International. ASTM E1245-03 - Standard Practice for Determining the Inclusion or Second Phase Constituent Content of Metals by Automatic Image Analysis. West Conshohocken: ASTM; 2003.

24. Schwind M, Källqvist J, Nilsson JO, Ågren J, Andrén HO. s-phase precipitation in stabilized austenitic stainless steels. Acta Materiallia. 2000;48(10):2473-2481.

25. Haskel HL, Sanches LS, Zempulski PRS, Ponte HA. Avaliação da Técnica de Voltametria Linear para Determinação Quantitativa de Fase Sigma no Aço Inoxidável Duplex UNS S31803. Soldagem \& Inspeção. 2015;20(3):333-346. 